\title{
Sir Edward Appleton, G.B.E., K.C.B., F.R.S. 1892-1965
}

It is with great sadness that we must record the passing of Sir Edward Appleton. It is safe to say that his total contributions to radio science have been without equal. The high point of his career was the award in 1947 of the Nobel Prize for Physics.

As long ago as 1924, Appleton displayed his great scientific ingenuity and experimental skill when he demonstrated the existence of the Heaviside layer as an ionized region of the atmosphere capable of reflecting radio waves. From this time on, he conducted a continuous series of ionospheric researches which, among other things, helped lay the foundations of radar. Of his many theoretical contributions, we might mention his important developments in magneto-ionic theory.

During World War II, Appleton served as secretary of the Department of Scientific and Industrial Research. In addition, he contributed in a significant way to the British atomic energy program. He was president of URSI from 1932 until 1952.

In his lifetime Sir Edward has received many honors including the Morris Liebmann Prize (1929), Hughes Medal of Royal Society (1933), Royal Medal (1950), Faraday Medal (1946), Ewing Medal (1949), Victoria Jubilee Prize (1960), IRE Medal of Honor (1962), and the Kelvin Medal (1963). At the time of his death (April 22, 1965), he was Principal and Vice-Chancellor of Edinburgh University and he was Editor of the Journal of Atmospheric and Terrestrial Physics. 